\title{
Transcranial Alternating Current Stimulation Modulates Risky Decision Making in a Frequency-Controlled Experiment
}

\author{
Dachary Yaple, ${ }^{1}$ [D Mario Martinez-Saito, ${ }^{1}$ Bhuvanesh Awasthi, ${ }^{1}$ ํㅣㄹatteo Feurra, ${ }^{1,2}$

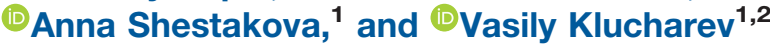

\section{DOI:http://dx.doi.org/10.1523/ENEURO.0136-17.2017}

${ }^{1}$ Centre for Cognition and Decision Making, National Research University Higher School of Economics, 20 Myasnitskaya Ulitsa, Moscow 109316, Russian Federation and ${ }^{2}$ School of Psychology, National Research University Higher School of Economics, Armyanskiy per.4,c2, Moscow 109316, Russian Federation

\begin{abstract}
In this study, we investigated the effect of transcranial alternating current stimulation (tACS) on voluntary risky decision making and executive control in humans. Stimulation was delivered online at $5 \mathrm{~Hz}(\theta), 10 \mathrm{~Hz}(\alpha), 20 \mathrm{~Hz}$ $(\beta)$, and $40 \mathrm{~Hz}(\gamma)$ on the left and right frontal area while participants performed a modified risky decision-making task. This task allowed participants to voluntarily select between risky and certain decisions associated with potential gains or losses, while simultaneously measuring the cognitive control component (voluntary switching) of decision making. The purpose of this experimental design was to test whether voluntary risky decision making and executive control can be modulated with tACS in a frequency-specific manner. Our results revealed a robust effect of a $20-\mathrm{Hz}$ stimulation over the left prefrontal area that significantly increased voluntary risky decision making, which may suggest a possible link between risky decision making and reward processing, underlined by $\beta$-oscillatory activity.
\end{abstract}

Key words: $20-\mathrm{Hz}$ stimulation; frontal hemisphere; reward; risky decision making; task switching; transcranial alternating current stimulation

\section{Significance Statement}

This is the first study that shows a frequency-specific effect on risky decision making demonstrated by online $20-\mathrm{Hz}$ transcranial alternating current stimulation (tACS) applied to left dorsolateral prefrontal cortex (PFC). Our results suggest that left frontal $20-\mathrm{Hz}$ tACS specifically modulates risky decision making, perhaps by entraining endogenous $\beta$-activity underlying a frontal-striatal network associated with gain anticipation.

\section{Introduction}

Much research has been conducted on the neurobiological mechanisms of risky decision making demonstrating a

Received April 19, 2017; accepted October 9, 2017; First published November 30, 2017.

The authors declare no competing financial interests.

Author contributions: Z.Y., M.F., A.S., B.A., and V.K. designed research; Z.Y. performed research; Z.Y. and M.M. analyzed data; Z.Y. wrote the paper.

The work was supported by the Russian Academic Excellence Project 5-100.

Acknowledgements: We thank Bhuvanesh Awasthi for his recommendations and expertise in task programming and for data collection. large neural network comprised of the ventral striatum, amygdala, insula, cingulate, and prefrontal cortices (PFCs; Knutson et al., 2001a,b; O’Doherty et al., 2001;

Correspondence should be addressed to Zachary Yaple at the above address, E-mail: zachyaple@gmail.com.

DOI:http://dx.doi.org/10.1523/ENEURO.0136-17.2017

Copyright $(2017$ Yaple et al.

This is an open-access article distributed under the terms of the Creative Commons Attribution 4.0 International license, which permits unrestricted use, distribution and reproduction in any medium provided that the original work is properly attributed. 
Kuhnen and Knutson, 2005; Rao et al., 2008; Fujiwara et al., 2009; Mohr et al., 2010; Kohls et al., 2013). In particular, the PFC plays an important role in voluntary risky decision making. For instance, Rao et al. (2008) demonstrated a link between the PFC and voluntary decisions to accept greater risk. They suggested that the PFC mediates the active volitional control or agency of the risk taker by means of an executive control component.

The PFC also plays a prominent role in executive control (Derrfuss et al., 2005; Swick et al., 2011; Kim et al., 2012; Rottschy et al., 2012; also, see Owen et al., 2005, for fMRI meta-analyses on executive functions), which in turn comprises of three separate, independent components; working memory updating, inhibition, and set shifting/task switching (Miyake et al., 2000; Diamond, 2013). Risky decision making and executive control have been thoroughly investigated. Inspired by Kahneman's dual process theory, that irrational decision making increases when cognitive resources become depleted (Kahneman, 2003; Kahneman and Frederick, 2007; Kahneman, 2011), some have tested the influence of executive control on risky decision making by administering the n-back task, a popular working memory task, in parallel with various risky decision-making tasks (Whitney, Rinehart and Hinson, 2008; Starcke et al., 2011; Farrell et al., 2012; Pabst et al., 2013; Gathmann et al., 2014a,b). Likewise, many have examined inhibitory processes and risky decision making by employing the Go No-Go (Verdejo-García et al., 2007; Yeomans and Brace, 2015; Ba et al., 2016; Welsh et al., 2017). However, to date few have examined the link between set-switching and risky decision making (Verdejo-García et al., 2007; Fröber and Dreisbach, 2016); therefore, we proposed to investigate this link by using brain stimulation of the PFC.

$\theta$-Related activity $(4-8 \mathrm{~Hz})$ has been inferred to reflect aspects of risky decision making and executive control. While numerous accounts have associated $\theta$-band oscillations with executive control functions (e.g., working memory, set-switching, conflict monitoring, error detection; Jensen and Tesche, 2002; Sauseng et al., 2006; Cunillera et al., 2012; Cavanagh and Frank, 2014), a recent EEG study reported fronto-central $\theta$-oscillations inferred to reflect an action monitoring system that compares potential outcomes of high- and low-risk options (Zhang et al., 2014). Furthermore, $\theta$-band transcranial alternating current stimulation (tACS) applied on the left PFC was demonstrated to increase risky decision making (Sela et al., 2012). This stimulation technique allegedly entrains ongoing electrophysiological oscillatory activity (Veniero et al., 2015; Vosskuhl et al., 2015; Thut et al., 2011; Helfrich et al., 2014a), suggesting that theta tACS entrains frontal-central theta oscillations. However, a disadvantage to this study is that frequency specificity could not be assessed since the authors did not control for other stimulation frequencies. In other words, the increase in risky decision making may have been driven by the stimulation alone and not necessarily by theta stimulation (for further details, see Feurra et al., 2012).

For this study, we tested whether voluntary risky decision making under varied levels of executive control can be modulated by applying online tACS at various frequencies (sham, 5, 10, 20, and $40 \mathrm{~Hz}$ ) to the left and right frontal hemispheres. To isolate these components of decision making, we adopted and modified a task-switching paradigm that allows participants to choose between risky and safe (certain) decisions depending on the decision to switch or repeat between task sets (Arrington and Logan, 2004, 2005; Weaver and Arrington, 2013; Arrington et al., 2014; Orr and Banich, 2014; Poljac and Yeung, 2014; Fröber and Dreisbach, 2016). Although relatively new for cognitive neuroscience (Orr and Banich, 2014; Poljac and Yeung, 2014), the voluntary taskswitching paradigm is well established within the cognitive psychological literature (Arrington and Logan, 2004, 2005; Weaver and Arrington, 2013; Fröber and Dreisbach, 2016). However, unlike typical executive tasks, in which participants are rated on response time and accuracy (e.g., N back, Go Go-No task, Eriksen Flanker task, Wisconsin Card Sorting task), the voluntary task-switching paradigm investigates voluntary executive control by considering choice as a dependent variable. By combining the voluntary task-switching paradigm with two-choice financial decision-making task between lotteries involving risk, it is possible to measure how much executive control participants are willing to exert under the condition of risk. The advantage of this task design was the possibility to measure voluntary executive control and voluntary risky decision making within a single response, thus allowing us to test whether tACS can modulate voluntary risky decision making under varied levels of voluntary executive control. Given that voluntary, but not involuntary, risky decision making yields frontal-ventral striatum activity (Rao et al., 2008), we hypothesize that $\theta$-band tACS should modulate voluntary risky decision making under high levels of executive control.

\section{Materials and Methods}

\section{Participants}

Thirty-four healthy right-handed participants (21 females; mean age 21 ; age range $18-26$ years; $S D=2.54$ ) with normal or corrected to normal vision and with no neurologic disorders participated in the study. All participants provided a written consent approved by a local ethics committee in accordance with the Declaration of Helsinki. All participants were screened for psychological/ psychiatric disorders and none of them reported use of drugs or alcohol in the days preceding the experiment. Participants were divided into two groups: those who received stimulation on the left frontal area $(n=17 ; 10$ females; mean age 20.52; age range 18-25 years; $S D=$ 2.52) and those who received stimulation on the right frontal area $(n=17 ; 11$ females; mean age 21.17; age range $18-26$ years; $S D=2.78$ ).

\section{Stimuli and procedure}

Participants performed a novel neuroeconomic risky decision-making task that combines binary lotteries with equal expected value (Selten et al., 1999; Engelmann and Tamir, 2009; Harrison et al., 2013), and the voluntary 
A

Trial $n-1 \quad$ Repeat trial (selection of certain option)

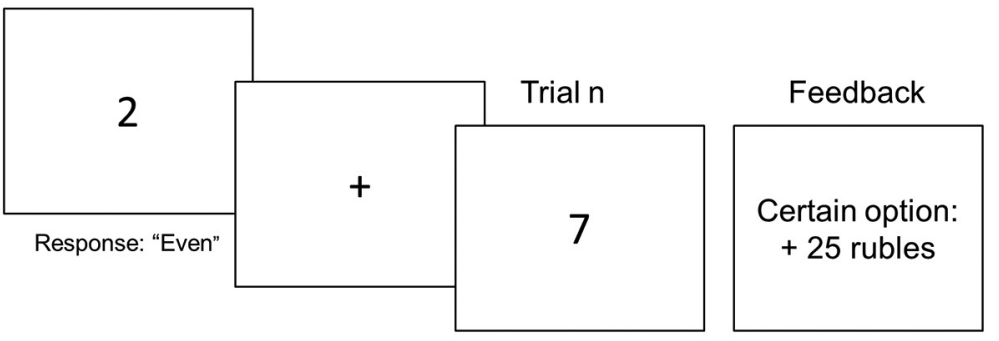

Response: "Odd"

Trial $n-1$ Switch trial (selection of risky option)

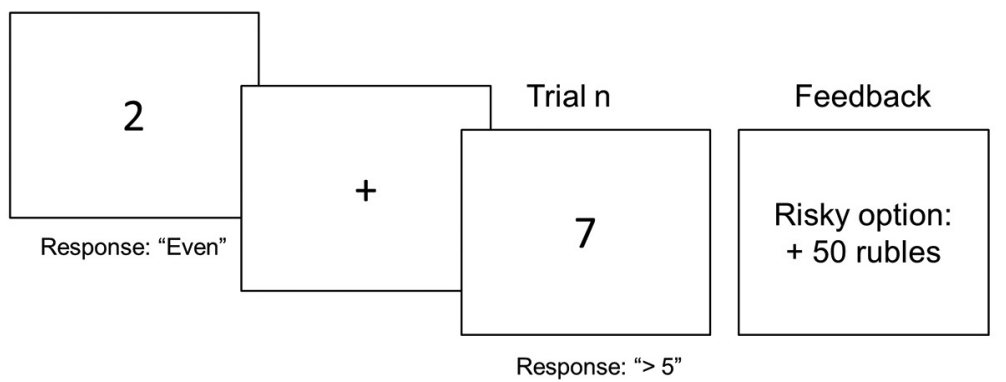

B

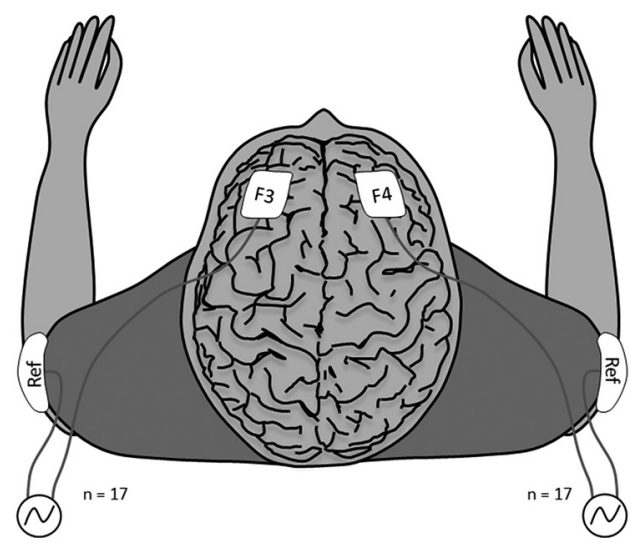

Figure 1. $\boldsymbol{A}$, Rewarded voluntary switch task, a combined risky decision-making and task-switching paradigm. In trial N, subjects may select the certain decision (25 RUB with a probability of $100 \%$ ) or the risky decision (50 RUB or 0 RUB with a probability of $50 \%$ ) depending on decision to switch or repeat task sets from trial $\mathrm{N}-1$. Figure represents trial in the reward switch $=$ risk block. $\boldsymbol{B}$, tACS montage. Active electrodes were placed on F3 and F4 electrode, representing left and right frontal area. Placement of the reference electrode was the ipsilateral deltoid for F3 and F4.

task-switching paradigm (Arrington and Logan, 2004, 2005) that allows participants to select between risky or certain decisions by switching or repeating task sets between trials. Each trial began with a centered fixation cross which remained between 500 and 1000 ms followed by the stimuli screen, composed of a randomly selected single digit $(1,2,3,4,6,7,8$, or 9) centered on the screen until the participant responded. For each trial participants had to select one of the two games: odd/even game (participants indicated whether the digit was odd or even) or higher/lower game (participants indicated whether the digit was higher or lower than 5) by pressing one of the corresponding buttons (odd, even, high, low). Using a randomized Latin-square blocked design, the instruction varied across blocks as described below.

In the basic version of the task (Fig. 1A, "switch = risk" blocks) participants were instructed that if they chose to repeat the same game in successive trials they would make a certain decision, e.g., they select "odd" button for the digit 3 on trial $\mathrm{N}-1$, and then "even" button for the digit 8 on trial $\mathrm{N}$, repeating the odd/even game. If the participant decided to alternate between game types, participants made a risky decision, e.g., they select "odd" button for the digit 3 on trial $\mathrm{N}-1$, and then "high" button for the digit 8 on trial $\mathrm{N}$, switching to the higher/lower game. Across half of the blocks these instructions were counterbalanced such that switching between games led to the certain decision and repeating the same game would yield the risky decision. In the Results section these block instructions are referred to as switch $=$ risk blocks and "repeat = risk" blocks. In other words, to select a risky decision, participants had to switch between games (switch = risk blocks), while in the other blocks (repeat $=$ risk blocks), participants had to repeat the same game.

Since gain-framed and loss-framed decisions differentially affect risk preferences (Tversky and Kahneman, 1985), the experiment was also divided into gain and loss blocks. In gain blocks, certain decisions were defined and instructed as " $100 \%$ probability that you would receive 25 Russian rubles (RUB)", while risky decisions were defined and instructed as " $50 \%$ probability that you would receive 50 RUB" (or alternatively 0 RUB). In loss blocks, the certain decision indicated " $100 \%$ probability that you would lose 25 RUB" while risky decisions indicated " $50 \%$ probability that you would lose 50 RUB" (alternatively 0 RUB). For each response that determined the game they selected, a feedback screen displayed for $1000 \mathrm{~ms}$ indicated the amount of money gained or lost for that particular trial. If response time exceeded $4000 \mathrm{~ms}$ or participants responded erroneously, feedback for that particular trial displayed negative feedback (e.g., 0 RUB for gain block, -50 RUB for loss blocks).

Similarly to the voluntary switching task, response buttons were counterbalanced across participants (Arrington and Logan, 2004). Block condition were counterbalanced in random order. Presentation of stimuli and recording of responses were controlled by E-Prime 2.0 software. All text was displayed in black font on a gray scale background and all participants were instructed to use two 
hands to respond. Due to the difficulty of the task and to avoid learning effects, participants received two rounds of training, which consisted of eight blocks of 10 trials, resulting in 80 trials in total. If accuracy was below 95\% additional training sessions were given. This learning phase was reflected in the actual experiment in which accuracy for all participants throughout the task was above $92 \%$. After training, participants received 20 blocks of 20 trials each. At the end of the experiment participants were shown the total cumulative feedback on the computer screen. Participants received 500 RUB for participation $(500$ RUB $\approx$ 7 United States dollar) and an additional bonus, between -300 and +300 RUB, based on the feedback outcomes of six randomly selected trials to maintain an equal motivation for risky decision making across blocks (Krajbich et al., 2012).

\section{tACS procedure}

By using the international electroencephalography 10-20 system, tACS was applied on the left or right frontal areas by placing a $7 \times 5-\mathrm{cm}$ saline-soaked electrode on F3 or F4 locations (Fig. 1B). For both location sites, a reference electrode was placed on the ipsilateral deltoid to the target electrode (Im et al., 2012; Bai et al., 2014). The order of stimuli was randomized across 20 blocks. Standard protocols were employed as in previous frequencycontrolled tACS experiments on motor and cognitive tasks (sham, 5, 10, 20, and $40 \mathrm{~Hz}$; Feurra et al., 2011, 2016; Santarnecchi et al., 2013, 2016), accounting for mean center frequencies (Klimesch, 2012). Furthermore, tACS set at a fixed frequency has been shown to entrain individualized $\alpha$-oscillations converging to a $10-\mathrm{Hz}$ stimulation (Helfrich et al., 2014a). Therefore, we contend that these frequency stimulations suffice to entrain endogenous neural oscillations within standard $\theta, \alpha, \beta$, and $\gamma$ ranges, respective of individual frequency ranges.

Stimulation was delivered online during task performance, with exception to sham stimulation, which lasted for $30 \mathrm{~s}$. To implement a sham stimulation, instead of using a fixed frequency that may bias a single stimulation protocol over another, we applied sinusoidal low-frequency transcranial random noise stimulation (tRNS) between 0.1 and $100 \mathrm{~Hz}$ for $30 \mathrm{~s}$. This sham stimulation protocol was necessary in the current experiment due to the unconventional use of multiple stimulation protocols reflecting the harmonics of mean center frequencies (Klimesch, 2012). Furthermore, it is important to emphasize that lowfrequency tRNS was applied only for a short duration, compared to all other protocols that were applied throughout the entire block; sham stimulation was delivered for $30 \mathrm{~s}$ with 10-s fade-in/fade-out, while all other stimulation protocols lasted between 5 and $10 \mathrm{~min}$. Moreover, low-frequency tRNS has been shown not to affect cortical excitability (Paulus, 2011). Stimulation current was set at $1 \mathrm{~mA}$ (500 mA peak-to-peak). The maximum current density at the stimulation electrode was $\sim 14 \mu \mathrm{A} /$ $\mathrm{cm}^{2}$. The wave form of the stimulation was sinusoidal, and there was no direct current offset. The low intensity of stimulation was used to avoid a perception of flickering lights (Paulus, 2010). Stimulation was delivered using a battery-operated stimulator system (BrainStim, EMS Medical). Impedance was kept below $10 \mathrm{k} \Omega$. All protocols began one minute before each block. Due to abundant evidence that tACS affects physiologic activity during stimulation (Antal et al., 2008; Helfrich et al., 2014a,b; Strüber et al., 2015), breaks of 5 min were given after each set of four blocks. In total, stimulation lasted $\sim 40 \mathrm{~min}$.

\section{Statistical analysis}

Analysis was performed using $R$ software $(R$ Core Team, 2016) with the software package Ime4 (Bates et al., 2014) and Imertest (Kuznetsova et al., 2016). Two separate logistic regression mixed models (Generalized Linear Mixed Model) on the raw data were performed on the following variables: (1) selection of risky decisions and (2) selection of switches between trials. Each model included the following categorical predictors: valence (gain, loss blocks), switch condition (switch $=$ risk blocks and repeat $=$ risk), frequency of stimulation (sham, $5,10,20$, and $40 \mathrm{~Hz}$ ) with sham as a reference variable, and hemisphere of stimulation (left, right). Before analysis error trials and trials exceeding response time of four seconds were omitted. Wald tests (Kuznetsova et al., 2016) were performed on all levels up to two interactions. To account for possible group differences, sham stimulation was used as a reference variable for each effect associated with frequency. In the logistic regression model participants, valence, switch condition, and frequency of stimulation were modeled with random effects, while hemisphere of stimulation (a between-subjects factor) was modeled with fixed effects. The $\mathrm{R}$ command Ime4 function is as follows: glmer(Risk $\sim$ (Frequency + Valence + Hemi) $\wedge 2+(1+$ Frequency + Condition + Valence: Condition I Subject), family = "binomial", data $=\mathrm{D}$, control $=$ glmerControl (optimizer="bobyqa", optCtrl = list (maxfun = 2e5))). Significance for the regression coefficients was corrected for false positives by using Holm-Bonferroni procedure.

For the following analyses we used SPSS software version 20 (IBM Corp, 2011). A mixed ANOVA was performed on the mean response time of the following variables: valence (gain, loss blocks), frequency of stimulation (sham, 5, 10, 20, and $40 \mathrm{~Hz}$ ), switch condition (switch = risk blocks and repeat $=$ risk blocks), and hemisphere of stimulation (left- and right-stimulated group), in which switch condition, valence, and frequency of stimulation were within-participants factors and hemisphere of stimulation was treated as between participants factor. Sphericity was not violated across any of these effects (all $p>$ 0.05). To assess whether participants selected more risky decisions than chance level, a one-sample $t$ test was performed.

\section{Results}

Figure 2 displays the percentage of risky decisions in all stimulation conditions. The logistic regression mixed model for risky decision making revealed an increase in risky decision making during $20 \mathrm{~Hz}$ of stimulation particularly when stimulating the left PFC $(\beta=0.989 ; p=$ $0.00194 ; p^{\prime}=0.043$ ). The effects of other tACS frequencies on risky decision making did not survive Holm- 


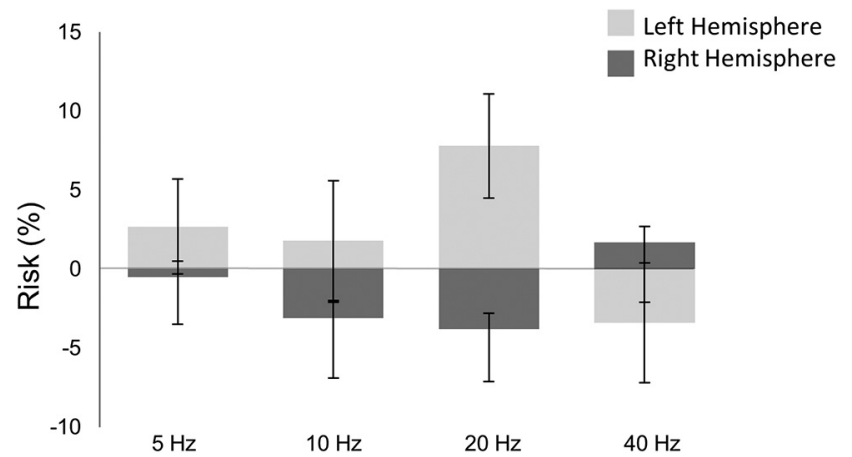

Figure 2. Mean percentage of risky decisions for each tACS condition with respect to sham; $20-\mathrm{Hz}$ stimulation of the left frontal area increased selection of voluntary risky decisions. Error bars correspond to SEM.
Bonferroni correction for multiple comparisons (Table 1). The frequency- and hemisphere-specific effect of a $20-\mathrm{Hz}$ stimulation was confirmed by a nonsignificant main effect of hemisphere of stimulation $\left(\beta=0.072, p=0.885 ; p^{\prime}>\right.$ 0.999). Figure 2 displays means and standard error for each of the comparisons with regards to the frequency of stimulation $\times$ hemisphere of stimulation interaction effect.

In addition, separate logistic regression models were performed using sham as a reference for each stimulation group (Table 2). The model for the left-stimulated group (Table 2) revealed a statistical significant increase in risky decision making from a $20-\mathrm{Hz}$ stimulation $(\beta=0.610, p=$ $0.001 ; p^{\prime}>0.021$ ). Follow-up analysis using $20 \mathrm{~Hz}$ as a reference (Table 3) revealed that $20 \mathrm{~Hz}$ of stimulation applied to the left hemisphere increased risky decision

Table 1. Results of the logistic regression for risky decision making and for voluntary switching

\begin{tabular}{|c|c|c|c|c|c|c|c|c|c|c|c|}
\hline \multicolumn{6}{|c|}{$\begin{array}{l}\text { Logistic regression model of risky decision } \\
\text { making (sham as reference variable) }\end{array}$} & \multicolumn{6}{|c|}{$\begin{array}{l}\text { Logistic regression model of voluntary } \\
\text { switching (sham as reference variable) }\end{array}$} \\
\hline & $\beta$ & SE & $z$ value & $p$ value & $p^{\prime}$ & & $\beta$ & SE & $z$ value & $p$ value & $p^{\prime}$ \\
\hline $5 \mathrm{~Hz}$ (sham) & 0.248 & 0.213 & 1.163 & 0.244 & $>0.99$ & $5 \mathrm{~Hz}$ (sham) & -0.196 & 0.170 & -1.153 & 0.249 & $>0.99$ \\
\hline $10 \mathrm{~Hz}$ (sham) & 0.172 & 0.287 & 0.600 & 0.548 & $>0.99$ & $10 \mathrm{~Hz}$ (sham) & -0.034 & 0.148 & -0.232 & 0.816 & $>0.99$ \\
\hline $20 \mathrm{~Hz}$ (sham) & 0.624 & 0.251 & 2.486 & 0.012 & 0.265 & $20 \mathrm{~Hz}$ (sham) & -0.054 & 0.138 & -0.394 & 0.693 & $>0.99$ \\
\hline $40 \mathrm{~Hz}$ (sham) & -0.204 & 0.283 & -0.720 & 0.471 & $>0.99$ & $40 \mathrm{~Hz}$ (sham) & -0.225 & 0.162 & -1.394 & 0.163 & $>0.99$ \\
\hline Switch Cond & -0.496 & 0.234 & -2.118 & 0.034 & 0.581 & Switch Cond & 2.005 & 0.103 & 19.361 & $<2 \times 10^{-16}$ & $<0.001$ \\
\hline Hemisphere $(L-R)^{a}$ & 0.072 & 0.501 & 0.144 & 0.885 & $>0.99$ & Hemisphere $(\mathrm{L}-\mathrm{R})^{\mathrm{a}}$ & -0.402 & 0.198 & -2.031 & 0.042 & 0.714 \\
\hline Valence (gain-loss) & 0.693 & 0.476 & 1.455 & 0.145 & $>0.99$ & Valence (gain-loss) & -0.110 & 0.103 & -1.068 & 0.285 & $>0.99$ \\
\hline $5 \mathrm{~Hz} *$ (gain-loss) & -0.156 & 0.132 & & & $>0.99$ & $5 \mathrm{~Hz} *$ (gain-loss) & & & & & $>0.99$ \\
\hline 10 Hz* (gain-loss) & -0.305 & 0.133 & -2.284 & 0.022 & 0.425 & $10 \mathrm{~Hz} *$ (gain-loss) & 0.258 & 0.119 & 2.163 & 0.030 & 0.540 \\
\hline $20 \mathrm{~Hz} *$ (gain-loss) & -0.166 & 0.133 & -1.247 & 0.212 & $>0.99$ & $20 \mathrm{~Hz} *$ (gain-loss) & 0.058 & 0.120 & 0.486 & 0.626 & $>0.99$ \\
\hline 40 Hz* (gain-loss) & -0.233 & 0.131 & & & & & & & & & $>0.99$ \\
\hline $5 \mathrm{~Hz} *$ Switch Cond & -0.125 & 0.132 & -0.945 & 0.344 & $>0.99$ & $5 \mathrm{~Hz} *$ Switch Cond & 0.083 & 0.123 & 0.676 & & $>0.99$ \\
\hline $10 \mathrm{~Hz} *$ Switch Cond & 0.076 & 0.133 & 0.573 & 0.566 & $>0.99$ & $10 \mathrm{~Hz} *$ Switch Cond & -0.174 & 0.120 & -1.450 & & $>0.99$ \\
\hline $20 \mathrm{~Hz} *$ Switch Cond & 0.003 & 0.133 & 0.026 & 0.979 & $>0.99$ & $20 \mathrm{~Hz} *$ Switch Cond & 0.113 & 0.122 & 0.930 & 0.352 & $>0.99$ \\
\hline $40 \mathrm{~Hz} *$ Switch Cond & -0.026 & 0.131 & -0.205 & 0.837 & $>0.99$ & $40 \mathrm{~Hz} *$ Switch Cond & -0.126 & 0.122 & -1.032 & 0.302 & $>0.99$ \\
\hline $5 \mathrm{~Hz} *(\mathrm{~L}-\mathrm{R})^{\mathrm{a}}$ & 0.202 & 0.270 & 0.747 & 0.455 & $>0.99$ & $5 \mathrm{~Hz} *(\mathrm{~L}-\mathrm{R})^{\mathrm{a}}$ & -0.185 & 0.202 & -0.915 & 0.360 & $>0.99$ \\
\hline $10 \mathrm{~Hz} *(\mathrm{~L}-\mathrm{R})^{\mathrm{a}}$ & 0.418 & 0.384 & 1.091 & 0.275 & $>0.99$ & $10 \mathrm{~Hz} *(\mathrm{~L}-\mathrm{R})^{\mathrm{a}}$ & -0.153 & 0.166 & -0.919 & 0.358 & $>0.99$ \\
\hline $20 \mathrm{~Hz} *(\mathrm{~L}-\mathrm{R})^{\mathrm{a}}$ & 0.989 & 0.319 & 3.099 & 0.001 & 0.043 & $20 \mathrm{~Hz} *(\mathrm{~L}-\mathrm{R})^{\mathrm{a}}$ & -0.027 & 0.147 & -0.190 & 0.849 & $>0.99$ \\
\hline $40 \mathrm{~Hz} *(\mathrm{~L}-\mathrm{R})^{\mathrm{a}}$ & -0.276 & 0.380 & -0.726 & 0.467 & $>0.99$ & $40 \mathrm{~Hz} *(\mathrm{~L}-\mathrm{R})^{\mathrm{a}}$ & -0.353 & 0.187 & -1.884 & 0.059 & 0.944 \\
\hline Switch Cond* (gain-loss) & -0.385 & 0.154 & -2.494 & 0.012 & 0.265 & Switch Cond* (gain-loss) & -0.311 & 0.076 & -4.082 & $4.47 \times 10^{-5}$ & 0.001 \\
\hline Switch Cond $*(L-R)^{a}$ & -0.284 & 0.305 & -0.931 & 0.351 & $>0.99$ & Switch Cond $*(L-R)^{a}$ & 0.908 & 0.076 & 11.799 & $<2 \times 10^{-16}$ & $<0.001$ \\
\hline$\left(\right.$ gain-loss)*(L-R) ${ }^{a}$ & 1.442 & 0.657 & 2.195 & 0.028 & 0.507 & $\left(\right.$ gain-loss)*(L-R) ${ }^{\mathrm{a}}$ & -0.215 & 0.076 & -2.822 & 0.004 & 0.076 \\
\hline
\end{tabular}

Each frequency is referenced to sham and for hemisphere, left-stimulated group $(\mathrm{L})$ is respect to right frontal stimulated group (R). $\beta=\beta$ coefficient; $\mathrm{SE}=$ SEM; $z$ value based on Wald test; $p$ ' indicates adjusted $p$ values by Holm-Bonferroni correction; bold text indicates significant $p$ values; Switch Cond: switch = risk blocks minus repeat $=$ risk blocks; sham as reference variable for frequency of stimulation; $a=$ includes predictor modeled as fixed effects.

Table 2. Logistic regression model of risky decision making for each group with sham as a reference variable

\begin{tabular}{|c|c|c|c|c|c|c|c|c|c|c|c|}
\hline \multicolumn{6}{|c|}{$\begin{array}{c}\text { Logistic regression model of risky decision making for left } \\
\text { hemisphere group (sham as reference variable) }\end{array}$} & \multicolumn{6}{|c|}{$\begin{array}{c}\text { Logistic regression model of risky decision making for right } \\
\text { hemisphere group (sham as reference variable) }\end{array}$} \\
\hline & $\beta$ & SE & $z$ value & $p$ value & $p^{\prime}$ & & $\beta$ & SE & $z$ value & $p$ value & $p^{\prime}$ \\
\hline $5 \mathrm{~Hz}$ (sham) & 0.160 & 0.241 & 0.661 & 0.508 & $>0.99$ & $5 \mathrm{~Hz}$ (sham) & 0.130 & 0.246 & 0.529 & 0.596 & $>0.99$ \\
\hline $10 \mathrm{~Hz}$ (sham) & 0.309 & 0.283 & 1.091 & 0.275 & $>0.99$ & $10 \mathrm{~Hz}$ (sham) & -0.383 & 0.340 & -1.127 & 0.259 & $>0.99$ \\
\hline $20 \mathrm{~Hz}$ (sham) & 0.610 & 0.239 & 2.545 & 0.001 & 0.021 & $20 \mathrm{~Hz}$ (sham) & -0.352 & 0.326 & -1.079 & 0.280 & $>0.99$ \\
\hline $40 \mathrm{~Hz}$ (sham) & -0.065 & 0.299 & -0.219 & 0.826 & $>0.99$ & $40 \mathrm{~Hz}$ (sham) & -0.114 & 0.318 & -0.359 & 0.719 & $>0.99$ \\
\hline Switch Cond & -0.361 & 0.319 & -1.131 & 0.258 & $>0.99$ & Switch Cond & -0.371 & 0.199 & -1.865 & 0.062 & 0.868 \\
\hline Valence (gain-loss) & 0.672 & 0.341 & 1.970 & 0.048 & 0.672 & Valence (gain-loss) & -0.844 & 0.661 & -1.277 & 0.201 & $>0.99$ \\
\hline $5 \mathrm{~Hz} *$ (gain-loss) & 0.119 & 0.193 & 0.617 & 0.537 & $>0.99$ & $5 \mathrm{~Hz} *$ (gain-loss) & -0.350 & 0.184 & -1.900 & 0.057 & 0.855 \\
\hline $10 \mathrm{~Hz} *$ (gain-loss) & -0.373 & 0.192 & -1.937 & 0.052 & 0.676 & $10 \mathrm{~Hz} *$ (gain-loss) & -0.268 & 0.187 & -1.437 & 0.150 & $>0.99$ \\
\hline 20 Hz* (gain-loss) & 0.001 & 0.198 & 0.006 & 0.995 & $>0.99$ & $20 \mathrm{~Hz} *$ (gain-loss) & -0.273 & 0.183 & -1.489 & 0.136 & $>0.99$ \\
\hline 40 Hz* (gain-loss) & -0.207 & 0.190 & -1.093 & 0.274 & $>0.99$ & $40 \mathrm{~Hz} *$ (gain-loss) & -0.256 & 0.186 & -1.379 & 0.167 & $>0.99$ \\
\hline 5 Hz* Switch Cond & -0.217 & 0.193 & -1.125 & 0.260 & $>0.99$ & $5 \mathrm{~Hz} *$ Switch Cond & -0.040 & 0.183 & -0.223 & 0.823 & $>0.99$ \\
\hline $10 \mathrm{~Hz} *$ Switch Cond & -0.373 & 0.192 & -1.937 & 0.052 & 0.672 & $10 \mathrm{~Hz} *$ Switch Cond & 0.231 & 0.183 & 1.257 & 0.208 & $>0.99$ \\
\hline $20 \mathrm{~Hz} *$ Switch Cond & 0.001 & 0.198 & 0.006 & 0.995 & $>0.99$ & $20 \mathrm{~Hz} *$ Switch Cond & 0.085 & 0.180 & 0.474 & 0.635 & $>0.99$ \\
\hline $40 \mathrm{~Hz} *$ Switch Cond & -0.207 & 0.190 & -1.093 & 0.274 & $>0.99$ & $40 \mathrm{~Hz} *$ Switch Cond & 0.242 & 0.182 & 1.327 & 0.184 & $>0.99$ \\
\hline Switch Cond* (gain-loss) & -0.476 & 0.270 & -1.758 & 0.078 & 0.858 & Switch Cond* (gain-loss) & -0.281 & 0.209 & -1.340 & 0.180 & $>0.99$ \\
\hline
\end{tabular}

Results display $\beta$ coefficients $(\beta)$ with SE, $z$ score, original $p$ value, and corrected $p$ value ( $p$ ') for the following predictors: frequency $(5,10,20$, and 40 Hz and sham), switch condition (trials in which switch = risk minus trials in which repeat = risk), and valence (gain minus loss trials). All predictors were modeled with random effects. Bold text indicates significance after Holm-Bonferonni correction. 
Table 3. Logistic regression model of risky decision making with $20 \mathrm{~Hz}$ as a reference variable

\begin{tabular}{|c|c|c|c|c|c|}
\hline & $\beta$ & SE & $z$ value & $p$ value & $p^{\prime}$ \\
\hline Sham (20 Hz) & -0.624 & 0.251 & & & 0.216 \\
\hline & -0.375 & 0.240 & -1.565 & 0.117 & \\
\hline & 51 & 0.256 & & & \\
\hline & -0.828 & 0.291 & & & \\
\hline wit & -0.493 & 0.236 & & & 0.504 \\
\hline$(\mathrm{L}-\mathrm{R})^{\mathrm{a}}$ & 1.061 & 0.423 & & .012 & 0.216 \\
\hline & 0.526 & 0.476 & & & \\
\hline & 66 & 133 & & & \\
\hline & 9 & 0.134 & & & \\
\hline & -0.138 & 0.134 & & & $>0.99$ \\
\hline & -0.066 & 0.133 & & & $>0.99$ \\
\hline & -0.003 & 0.133 & & & \\
\hline & -0.128 & 0.134 & & & $>0.99$ \\
\hline & 0.073 & 0.134 & & & \\
\hline & -0.030 & 0.133 & & & $>0.99$ \\
\hline & -0.989 & 0.319 & & & 0.021 \\
\hline & -0.786 & 0.304 & & & 0.171 \\
\hline & -0.570 & 0.321 & -1.774 & & 0.975 \\
\hline & -1.265 & 0.374 & & & 0.015 \\
\hline $\begin{array}{r}\text { Switch } \\
\text { (gair }\end{array}$ & -0.385 & 0.154 & -2.495 & 0.012 & 0.216 \\
\hline & -0.284 & 0.305 & & & $>0.99$ \\
\hline & 1.442 & 0.656 & 2.198 & 0.027 & 0.405 \\
\hline
\end{tabular}

Results display $\beta$ coefficients $(\beta)$ with SE, $z$ score, original $p$ value, and corrected $p$ value $\left(p^{\prime}\right)$ for the following predictors: frequency $(5,10,20$, and 40 $\mathrm{Hz}$ and sham), switch condition (trials in which switch = risk minus trials in which repeat $=$ risk), valence (gain minus loss trials), and hemisphere of stimulation (left group minus right group). Frequency, switch condition, and valence were modeled as random effects; hemisphere of stimulation was modeled with fixed effects due to a between-subjects factor; $20 \mathrm{~Hz}$ as reference variable for frequency of stimulation; ${ }^{a}=$ includes predictor modeled as fixed effects; bold text indicates significance after Holm-Bonferonni correction.

making with respect to sham $(\beta=-0.989, p=0.001 ; p$ ' $>0.021)$ and $40-\mathrm{Hz}$ stimulation $(\beta=-1.265, p<0.001$; $\left.p^{\prime}>0.015\right)$. When separately testing hemisphere stimulation groups with $20 \mathrm{~Hz}$ as the reference variable, $20 \mathrm{~Hz}$ increased risky decision making compared to sham for the left-stimulated group $\left(\beta=-0.610, p=0.001 ; p^{\prime}>\right.$ 0.021 ; Table 4). No effects were found for the rightstimulated group (Table 4).

After Holm-Bonferroni correction, the logistic regression mixed model yielded no significant effects of tACS on voluntary switching, yet revealed a main effect of switch condition $\left(\beta=2.005 ; p \leq 2 \times 10^{-16} ; p^{\prime}<0.001\right)$, an interaction effect of switch condition $\times$ valence $(\beta=$ $-0.311 ; p=4.47 \times 10^{-5} ; p^{\prime}=0.001$ ), and an interaction effect of switch condition $\times$ hemisphere of stimulation $\left(\beta=0.908 ; p \leq 2 \times 10^{-16} ; p^{\prime}<0.001\right)$. These effects indicate an increase in voluntary switching in the switch = risk blocks compared to repeat $=$ risk blocks, especially for loss blocks; perhaps reflecting an influence of executive control on the framing bias. The interaction effect of switch condition and Hemisphere may demonstrate an increase in voluntary switching during switch $=$ risk blocks compared to repeat $=$ risk blocks from the leftstimulated group, yet should be interpreted with caution since Hemisphere of stimulation was modeled with fixed effects (see Discussion for details). Analysis of response times revealed that participants responded more slowly in trials in which switching between tasks led to risk $(\mu=$ $1112.43 \mathrm{~ms})$ compared to trials in which repeating led to risk $\left(\mu=988.98 \mathrm{~ms} ; F_{(1,32)}=17.455 ; p<0.001\right.$, partial $\eta^{2}=$ $0.353)$. Since participants overall were more likely to select risky decisions $(\mu=63.6 \%$; SE $=0.004$; one-sample $t$ test: $t=33.037 ; p<0.001$ ), we infer that this observed difference in response time is likely due to switching costs (for a detailed account on the voluntary switch cost, see Arrington et al., 2014).

In addition, the mixed ANOVA on response time revealed a main effect of valence $\left(F_{(1,32)}=25.842 ; p<\right.$ 0.001 , partial $\eta^{2}=0.447$ ), showing slower mean response times in loss blocks ( $\mu=1085.96 \mathrm{~ms}$ ) compared to gain blocks ( $\mu=1015.44 \mathrm{~ms}$ ). This significant difference may

Table 4. Logistic regression model of risky decision making for each group with $20 \mathrm{~Hz}$ as a reference variable

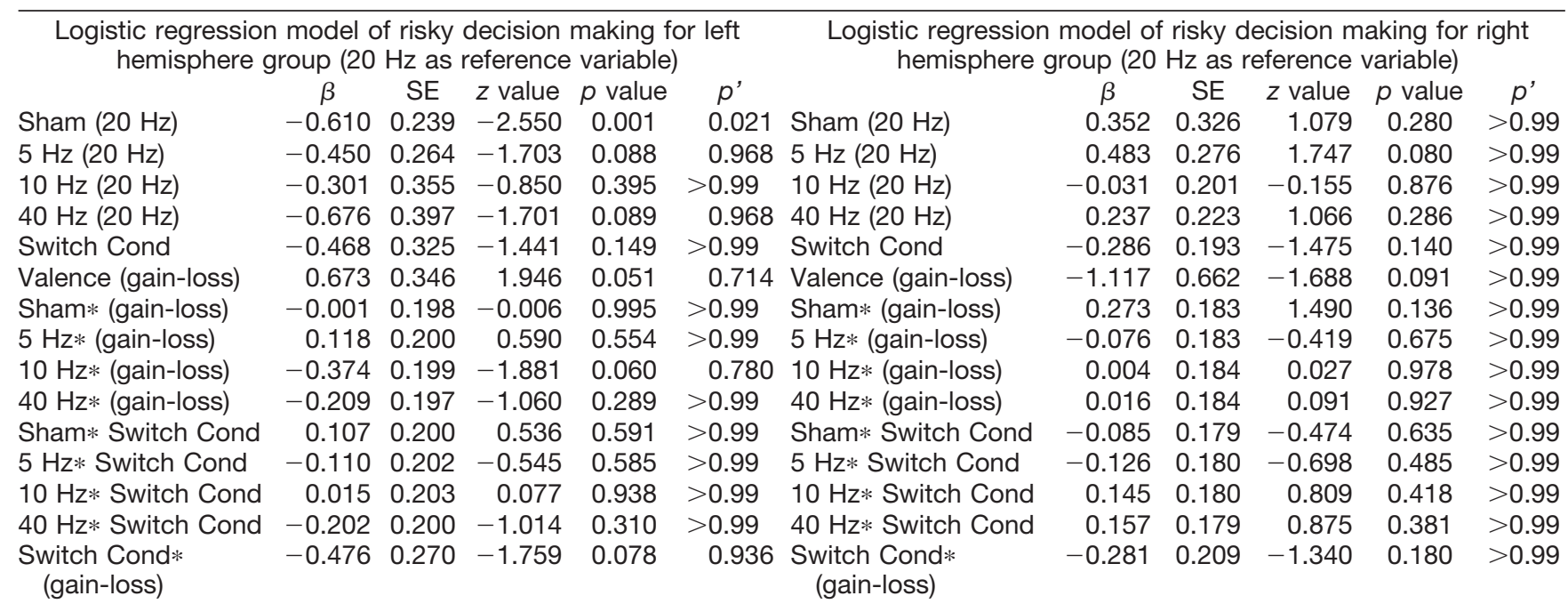

Results display $\beta$ coefficients $(\beta)$ with SE, $z$ score, original $p$ value, and corrected $p$ value ( $\left.p^{\prime}\right)$ for the following predictors: frequency $(5,10,20$, and 40 Hz and sham), switch condition (trials in which switch = risk minus trials in which repeat $=$ risk), and valence (gain minus loss trials). All predictors were modeled with random effects. 


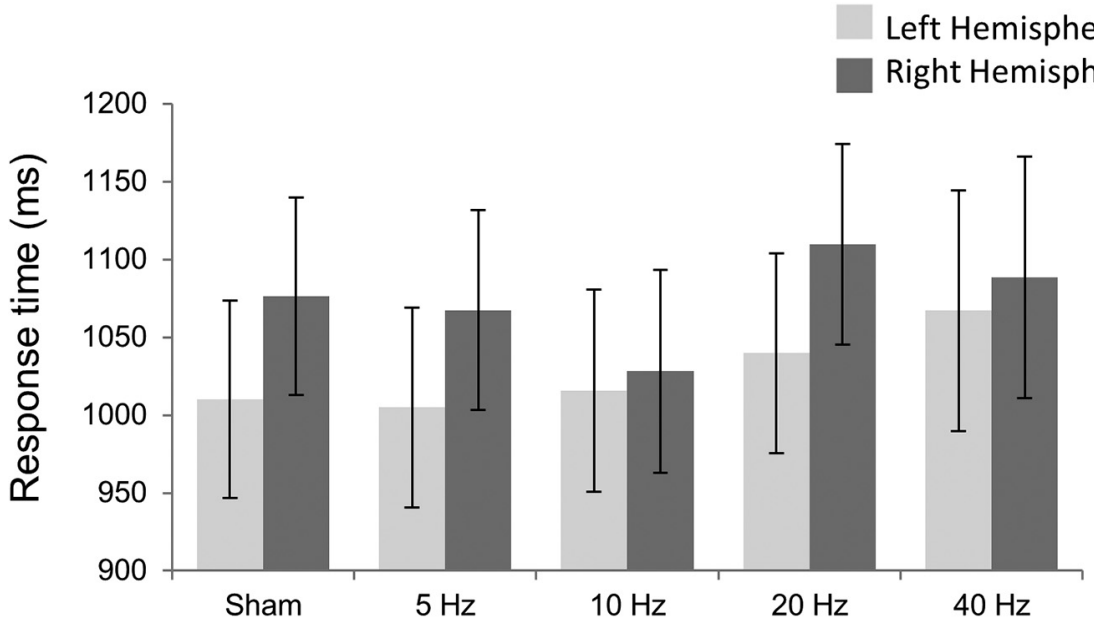

Figure 3. Mean response times for each Hemisphere group across frequency stimulation.

indicate increased deliberation in loss blocks. No other effects on reaction times were significant. See Figure 3 and Table 5 for list of response times for each condition.

\section{Discussion}

In the attempt to modulate oscillatory activity underling voluntary risky decision making and executive control we applied tACS (sham, 5, 10, 20, and $40 \mathrm{~Hz}$ ) to the left and right PFC while participants performed a modified risky decision-making task that requires choosing between risky and certain decisions by switching or repeating task sets. The analyses of risky decision making revealed several significant effects, yet the influence of a $20-\mathrm{Hz}$ stimulation on risky decision making was the most robust, surviving Holm-Bonferroni correction. Although frequency specificity has been demonstrated with $20-\mathrm{Hz}$ tACS for motor (Pogosyan et al., 2009; Feurra et al., 2011, Joundi et al., 2012) and sensory functions (Kanai et al., 2008, 2010; Turi et al., 2013), the current experiment is the first to reveal a frequency-specific increase in voluntary risky decision making from $20-\mathrm{Hz}$ tACS.

Within recent years, EEG studies investigating oscillatory activity in gambling tasks have demonstrated a correspondence between frontal $\beta$-oscillations $(20-35 \mathrm{~Hz})$ and anticipation of probable rewards (Bunzeck et al., 2011), as well as receiving unexpected rewarded feedback (Marco-Pallares et al., 2008; HajiHosseini et al., 2012; HajiHosseini and
Holroyd, 2015; Mas-Herrero et al., 2015). Marco-Pallarés et al. (2015) proposed that frontal $\beta$-oscillatory activity during gambling paradigms might signify the functional coupling between cortical and subcortical regions such as the ventral striatum, known to be involved in reward processing. This was recently confirmed in an EEG-fMRI study that reported correspondence between mid-frontal $\beta$-oscillatory activity and engagement of the fronto-striatalhippocampal network (Mas-Herrero et al., 2015). This may indicate that $20 \mathrm{~Hz}$ of stimulation increased motivation to select risky decisions by indirectly affecting brain regions of the reward system, such as the ventral striatum. Importantly, the ventral striatum is a key subcortical region for risky decision making since the activation of this area predicts risky decision making and increases in activation as rewards become more probable (Knutson and Greer, 2008; Niv et al., 2012). Taken together, we speculate that stimulation of the frontal cortex with $20-\mathrm{Hz}$ tACS may have resulted in a boost in reward-related processes involving the ventral striatum, thus resulting to an increase in voluntary risky decision making. Further support for this claim derives from electrical simulations of the left PFC (F3, EEG 10-20 system) with an extracephalic electrode placed on the shoulder demonstrating modulation of the PFC and deep medial structures (Bai et al., 2014).

Table 5. Mean response times associated with each hemisphere group across frequency stimulation

\begin{tabular}{|c|c|c|c|c|c|}
\hline \multirow[b]{2}{*}{ Hemisphere } & \multirow[b]{2}{*}{ Frequency } & \multirow[b]{2}{*}{ Mean } & \multirow[b]{2}{*}{ SE } & \multicolumn{2}{|c|}{$95 \%$ confidence interval } \\
\hline & & & & Lower bound & Upper bound \\
\hline \multirow[t]{5}{*}{ Right } & Sham & 1009.92 & 63.41 & 880.75 & 1139.09 \\
\hline & $5 \mathrm{~Hz}$ & 1004.91 & 64.29 & 873.96 & 1135.86 \\
\hline & $10 \mathrm{~Hz}$ & 1015.71 & 65.06 & 883.19 & 1148.23 \\
\hline & $20 \mathrm{~Hz}$ & 1039.81 & 64.26 & 908.91 & 1170.71 \\
\hline & $40 \mathrm{~Hz}$ & 1067.01 & 77.55 & 909.05 & 1224.98 \\
\hline \multirow[t]{5}{*}{ Left } & Sham & 1076.12 & 63.41 & 946.95 & 1205.29 \\
\hline & $5 \mathrm{~Hz}$ & 1067.47 & 64.29 & 936.52 & 1198.42 \\
\hline & $10 \mathrm{~Hz}$ & 1028.15 & 65.06 & 895.63 & 1160.66 \\
\hline & $20 \mathrm{~Hz}$ & 1109.68 & 64.26 & 978.79 & 1240.58 \\
\hline & $40 \mathrm{~Hz}$ & 1088.27 & 77.55 & 930.30 & 1246.23 \\
\hline
\end{tabular}


It is important to underline that although several effects involving hemisphere of stimulation were statistically significant, these effects should be generalized to the population cautiously since we used a between group design combining random effects (valence, switch condition, and frequency of stimulation) with fixed effects (Hemisphere of stimulation). Importantly, the specific effect of $20-\mathrm{Hz}$ tACS of the left PFC on risky decision making was further confirmed by separate statistical analyses for the left- and right-side stimulation (Table 2). Another potential caveat to the study is that potential after-effects of tACS cannot be ruled out as no simultaneous EEG recording took place. Despite the growing evidence that tACS effects neural oscillatory activity online (Antal et al., 2008; Helfrich et al., 2014a,b; Strüber et al., 2015), it was not possible to control within the current experiment.

The results of the current study seem contradictory to a previous study using tACS on risky decision making (Sela et al., 2012). However, the effect of $\theta$-band tACS in the previous study (Sela et al., 2012) could be due to a modulation of feedback-related adjustments (Cavanagh et al., 2010; Cavanagh et al., 2012; Luft, 2014; Zhang et al., 2014) since the previous tACS paper used the Balloon Analog Risk Task, which measures risk-taking propensity across a cumulative number of responses, as opposed to measuring risky decision making within a single response, as in the current study. A possible explanation for the alternate results may be due to the differences in montage. For instance, a previous study that modulated executive functions, specifically working memory, stimulated both frontal and parietal areas using an F3-P3 montage (Polanía et al., 2012). We suggest that stimulation of the frontal lobe may modulate either a frontal-striatal network associated with voluntary risky decision making (Rao et al., 2008) or a frontal-parietal network in association with voluntary executive control (Orr and Banich, 2014) depending on the placement of the reference electrode (Bai et al., 2014). Whereas the F3-EC (extracephalic) montage used in the current study likely modulates frontal and deep medial structures, an F3-P3 montage likely modulates frontal and parietal structures (Bai et al., 2014). Therefore, modulation of voluntary executive control may require an F3-P3 montage. Some have reported that the ratio of $\theta$ - and $\beta$-oscillations at resting state can be used to predict risk preferences in individuals (Schutter and van Honk, 2005; Massar et al., 2014). Therefore, it is also plausible that both $\theta$ - and $\beta$-band stimulation may modulate different cognitive components of the decision-making process within different states and/or contexts. Alternatively, one may suggest that the $20-\mathrm{Hz}$ stimulation could modulate working memory during risky decision making. Some studies suggest that risky decision making is associated with the capacity to maintain and organize information in working memory as an estimation of executive processes (Brevers et al., 2014a,b). Unfortunately, our study design did not allow testing of this hypothesis. However, we think that a modulation of working memory should not affect our results since subjects continued to receive training until their performance became above $95 \%$, as specified in the stimuli and procedure section, thereby eliminating potential confound learning effects and an overload of working memory.

Finally, our findings are consistent with the previous studies demonstrating that laterality (left and right frontal hemisphere) strongly influences the effect of voluntary risky decision making (Knoch et al., 2006; Fecteau et al., 2007a,b; Sela et al., 2012; Cheng and Lee, 2016). Together, these previous studies show that exciting the left and/or inhibiting the right PFC increasing risky decision making and vice versa. This suggests that a $20-\mathrm{Hz}$ stimulation increases cortical excitability of the left frontal area, presumably by entraining the frontal-striatal network. Together these results offer novel insight into the role of $\beta$-oscillatory activity in neural mechanisms of risky decision making.

\section{References}

Antal A, Boros K, Poreisz C, Chaieb L, Terney D, Paulus W (2008) Comparatively weak after-effects of transcranial alternating current stimulation (tACS) on cortical excitability in humans. Brain Stimul 1:97-105. CrossRef

Arrington CM, Logan GD (2004) The cost of a voluntary task switch. Psych Sci 15:610-615. CrossRef Medline

Arrington CM, Logan GD (2005) Voluntary task switching: chasing the elusive homunculus. J Exp Psychol Learn Mem Cogn 31:683. CrossRef Medline

Arrington CM, Reiman KM, Weaver SM (2014) Voluntary task switching. In: Task switching (Grange J, Houghton G, ed), pp 117-136. Oxford: Oxford University Press.

Ba Y, Zhang W, Salvendy G, Cheng AS, Ventsislavova P (2016) Assessments of risky driving: a Go/No-Go simulator driving task to evaluate risky decision-making and associated behavioral patterns. Appl Ergon 52:265-274. CrossRef Medline

Bai S, Dokos S, Ho KA, Loo C (2014) A computational modelling study of transcranial direct current stimulation montages used in depression. Neuroimage 87:332-344. CrossRef Medline

Bates D, Mächler M, Bolker B, Walker S (2014) Fitting linear mixedeffects models using Ime4. arXiv:1406.5823.

Brevers D, Bechara A, Cleeremans A, Kornreich C, Verbanck P, Noël $X$ (2014a) Impaired-decision making under risk in individuals with alcohol dependence. Alcohol Clin Exp Res, 38:1924-1931. Medline

Brevers D, Cleeremans A, Bechara A, Greisen M, Kornreich C, Verbanck P, Noël X (2014b) Impaired metacognitive capacities in individuals with problem gambling. J Gambl Stud, 30:141-152. Medline

Bunzeck N, Guitart-Masip M, Dolan RJ, Düzel E (2011) Contextual novelty modulates the neural dynamics of reward anticipation. $J$ Neurosci 31:12816-12822. CrossRef Medline

Cavanagh JF, Frank MJ (2014) Frontal theta as a mechanism for cognitive control. Trends Cogn Sci 18:414-421. CrossRef Medline

Cavanagh JF, Frank MJ, Klein TJ, Allen JJ (2010) Frontal theta links prediction errors to behavioral adaptation in reinforcement learning. Neuroimage 49:3198-3209. CrossRef Medline

Cavanagh JF, Figueroa CM, Cohen MX, Frank MJ (2012) Frontal theta reflects uncertainty and unexpectedness during exploration and exploitation. Cereb Cortex 22:2575-2586. CrossRef Medline

Cheng GL, Lee TM (2016) Altering risky decision-making: influence of impulsivity on the neuromodulation of prefrontal cortex. Soc Neurosci 11:353-364. CrossRef Medline

Cunillera T, Fuentemilla L, Periañez J, Marco-Pallarès J, Krämer UM, Càmara E, Münte TF, Rodríguez-Fornells A (2012) Brain oscillatory activity associated with task switching and feedback processing. Cogn Affect Behav Neurosci 12:16-33. CrossRef Medline

Derrfuss J, Brass M, Neumann J, Yves von Cramon D (2005) Involvement of the inferior frontal junction in cognitive control: meta- 
analyses of switching and Stroop studies. Hum Brain Mapp 25: 22-34. CrossRef

Diamond A (2013) Executive functions. Annu. Rev Psychol 64:135168. CrossRef Medline

Engelmann JB, Tamir D (2009) Individual differences in risk preference predict neural responses during financial decision-making. Brain Res 1290:28-51. CrossRef Medline

Farrell SM, Tunbridge EM, Braeutigam S, Harrison PJ (2012) COMT Val 158 Met genotype determines the direction of cognitive effects produced by catechol-O-methyltransferase inhibition. Biol Psychiatry 71:538-544. CrossRef Medline

Fecteau S, Knoch D, Fregni F, Sultani N, Boggio P, Pascual-Leone A (2007a) Diminishing risk-taking behavior by modulating activity in the prefrontal cortex: a direct current stimulation study. J Neurosci 27:12500-12505.

Fecteau S, Pascual-Leone A, Zald DH, Liguori P, Théoret H, Boggio PS, Fregni F (2007b) Activation of prefrontal cortex by transcranial direct current stimulation reduces appetite for risk during ambiguous decision making. J Neurosci 27:6212-6218.

Feurra M, Bianco G, Santarnecchi E, Del Testa M, Rossi A, Rossi S (2011) Frequency-dependent tuning of the human motor system induced by transcranial oscillatory potentials. J Neurosci 31:1216512170. CrossRef

Feurra M, Galli G, Rossi S (2012) Transcranial alternating current stimulation affects decision making. Front Syst Neurosci 6:39. CrossRef Medline

Feurra M, Galli G, Pavone EF, Rossi A, Rossi S (2016) Frequencyspecific insight into short-term memory capacity. J Neurophysiol 116:153-158. CrossRef Medline

Fröber K, Dreisbach G (2016) How sequential changes in reward magnitude modulate cognitive flexibility: evidence from voluntary task switching. J Exp Psychol Learn Mem Cogn 42:285-295. CrossRef Medline

Fujiwara J, Tobler PN, Taira M, lijima T, Tsutsui KI (2009) Segregated and integrated coding of reward and punishment in the cingulate cortex. J Neurophysiol 101:3284-3293. CrossRef Medline

Gathmann B, Pawlikowski M, Schöler T, Brand M (2014a) Performing a secondary executive task with affective stimuli interferes with decision making under risk conditions. Cogn Process 15:113-126.

Gathmann B, Schulte FP, Maderwald S, Pawlikowski M, Starcke K, Schäfer LC, Schöler T, Wolf OT, Brand M (2014b) Stress and decision making: neural correlates of the interaction between stress, executive functions, and decision making under risk. Exp Brain Res 232:957-973. CrossRef Medline

HajiHosseini A, Holroyd CB (2015) Reward feedback stimuli elicit high-beta EEG oscillations in human dorsolateral prefrontal cortex. Sci Rep 5:13021. CrossRef

HajiHosseini A, Rodríguez-Fornells A, Marco-Pallarés J (2012) The role of beta-gamma oscillations in unexpected rewards processing. Neuroimage 60:1678-1685. CrossRef Medline

Harrison GW, Martínez-Correa J, Swarthout JT (2013) Inducing risk neutral preferences with binary lotteries: a reconsideration. J Econ Behav Organ 94:145-159. CrossRef

Helfrich RF, Schneider TR, Rach S, Trautmann-Lengsfeld SA, Engel AK, Herrmann CS (2014a) Entrainment of brain oscillations by transcranial alternating current stimulation. Curr Biol 24:333-339. CrossRef Medline

Helfrich RF, Knepper H, Nolte G, Strüber D, Rach S, Herrmann CS, Schneider TR, Engel AK (2014b) Selective modulation of interhemispheric functional connectivity by HD-tACS shapes perception. PLoS Biol 12:e1002031.

IBM Corp (2011) Released. IBM SPSS statistics for windows, version 20.0. Armonk: IBM Corp.

Im CH, Park JH, Shim M, Chang WH, Kim YH (2012) Evaluation of local electric fields generated by transcranial direct current stimulation with an extracephalic reference electrode based on realistic 3D body modeling. Phys Med Biol 57:2137. CrossRef Medline

Jensen O, Tesche CD (2002) Frontal theta activity in humans increases with memory load in a working memory task. Eur $\mathrm{J}$ Neurosci 15:1395-1399. CrossRef Medline
Joundi RA, Jenkinson N, Brittain JS, Aziz TZ, Brown P (2012) Driving oscillatory activity in the human cortex enhances motor performance. Curr Biol 22:403-407. CrossRef Medline

Kahneman D (2003) A perspective on judgment and choice. Am Psychol 58:697-720. CrossRef Medline

Kahneman D (2011) Thinking, fast and slow. New York: Farrar, Straus and Giroux.

Kahneman D, Frederick S (2007) Frames and brains: elicitation and control of response tendencies. Trends Cogn Sci 11:45-46. CrossRef Medline

Kanai R, Chaieb L, Antal A, Walsh V, Paulus W (2008) Frequencydependent electrical stimulation of the visual cortex. Curr Biol 18:1839-1843. CrossRef Medline

Kanai R, Paulus W, Walsh V (2010) Transcranial alternating current stimulation (tACS) modulates cortical excitability as assessed by TMS-induced phosphene thresholds. Clin Neurophysiol 121: 1551-1554. CrossRef Medline

Kim C, Cilles SE, Johnson NF, Gold BT (2012) Domain general and domain preferential brain regions associated with different types of task switching: a meta-analysis. Hum Brain Mapp 33:130-142. CrossRef Medline

Klimesch W (2012) $\alpha$-Band oscillations, attention, and controlled access to stored information. Trends Cogn Sci 16:606-617. CrossRef Medline

Knoch D, Gianotti LR, Pascual-Leone A, Treyer V, Regard M, Hohmann M, Brugger P (2006) Disruption of right prefrontal cortex by low-frequency repetitive transcranial magnetic stimulation induces risk-taking behavior. J Neurosci 26:6469-6472. CrossRef

Knutson B, Adams CM, Fong GW, Hommer D (2001a) Anticipation of increasing monetary reward selectively recruits nucleus accumbens. J Neurosci 21:RC159.

Knutson B, Fong GW, Adams CM, Varner JL, Hommer D (2001b) Dissociation of reward anticipation and outcome with eventrelated fMRI. Neuroreport 12:3683-3687. Medline

Knutson B, Greer SM (2008) Anticipatory affect: neural correlates and consequences for choice. Philos Trans R Soc Lond B Biol Sci 363:3771-3786. CrossRef

Kohls G, Perino MT, Taylor JM, Madva EN, Cayless SJ, Troiani V, Price E, Faja S, Herrington JD, Schultz RT (2013) The nucleus accumbens is involved in both the pursuit of social reward and the avoidance of social punishment. Neuropsychologia 51:20622069. CrossRef Medline

Krajbich I, Lu D, Camerer C, Rangel A (2012) The attentional driftdiffusion model extends to simple purchasing decisions. Front Psychol 3:193. CrossRef

Kuhnen CM, Knutson B (2005) The neural basis of financial risk taking. Neuron 47:763-770. CrossRef Medline

Kuznetsova A, Brockhoff PB, Christensen, RHB (2016) "ImerTest Package: Tests in Linear Mixed Effects Models." Journal of Statistical Software, 82(13), pp. 1-26. CrossRef

Luft CD (2014) Learning from feedback: the neural mechanisms of feedback processing facilitating better performance. Behav Brain Res 261:356-368. CrossRef Medline

Marco-Pallares J, Cucurell D, Cunillera T, García R, Andrés-Pueyo A, Münte TF, Rodríguez-Fornells A (2008) Human oscillatory activity associated to reward processing in a gambling task. Neuropsychologia 46:241-248. CrossRef

Marco-Pallarés J, Münte TF, Rodríguez-Fornells A (2015) The role of high-frequency oscillatory activity in reward processing and learning. Neurosci Biobehav Rev 49:1-7. CrossRef Medline

Mas-Herrero E, Ripollés P, HajiHosseini A, Rodríguez-Fornells A, Marco-Pallarés J (2015) Beta oscillations and reward processing: coupling oscillatory activity and hemodynamic responses. Neuroimage 119:13-19. CrossRef Medline

Massar SA, Kenemans JL, Schutter DJ (2014) Resting-state EEG theta activity and risk learning: sensitivity to reward or punishment? Int J Psychophysiol 91:172-177. CrossRef Medline

Mohr PN, Biele G, Heekeren HR (2010) Neural processing of risk. J Neurosci 30:6613-6619. CrossRef Medline 
Miyake A, Friedman NP, Emerson MJ, Witzki AH, Howerter A, Wager TD (2000) The unity and diversity of executive functions and their contributions to complex "frontal lobe" tasks: a latent variable analysis. Cogn Psychol 41:49-100. CrossRef Medline

Niv Y, Edlund JA, Dayan P, O'Doherty JP (2012) Neural prediction errors reveal a risk-sensitive reinforcement-learning process in the human brain. J Neurosci 32:551-562. CrossRef

O'Doherty J, Kringelbach ML, Rolls ET, Hornak J, Andrews C (2001) Abstract reward and punishment representations in the human orbitofrontal cortex. Nat Neurosci 4:95-102.

Orr JM, Banich MT (2014) The neural mechanisms underlying internally and externally guided task selection. Neuroimage 84:191205. CrossRef Medline

Owen AM, McMillan KM, Laird AR, Bullmore E (2005) N-back working memory paradigm: a meta-analysis of normative functional neuroimaging studies. Hum Brain Mapp 25:46-59. CrossRef Medline

Pabst S, Schoofs D, Pawlikowski M, Brand M, Wolf OT (2013) Paradoxical effects of stress and an executive task on decisions under risk. Behav Neurosci 127:369-379. CrossRef Medline

Paulus W (2010) On the difficulties of separating retinal from cortical origins of phosphenes when using transcranial alternating current stimulation (tACS). Clin Neurophysiol 121:987-991. CrossRef Medline

Paulus W (2011) Transcranial electrical stimulation (tES-tDCS; tRNS, tACS) methods. Neuropsychol Rehabil 21:602-617. CrossRef Medline

Pogosyan A, Gaynor LD, Eusebio A, Brown P (2009) Boosting cortical activity at beta-band frequencies slows movement in humans. Curr Biol 19:1637-1641. CrossRef Medline

Polanía R, Nitsche MA, Korman C, Batsikadze G, Paulus W (2012) The importance of timing in segregated theta phase-coupling for cognitive performance. Curr Biol 22:1314-1318. CrossRef Medline

Poljac E, Yeung N (2014) Dissociable neural correlates of intention and action preparation in voluntary task switching. Cereb Cortex 24:465-478. CrossRef Medline

R Core Team (2016) R: a language and environment for statistical computing. Vienna: R Foundation for Statistical Computing.

Rao H, Korczykowski M, Pluta J, Hoang A, Detre JA (2008) Neural correlates of voluntary and involuntary risk taking in the human brain: an fMRI Study of the Balloon Analog Risk Task (BART). Neuroimage 42:902-910. CrossRef Medline

Rottschy C, Langner R, Dogan I, Reetz K, Laird AR, Schulz JB, Fox PT, Eickhoff SB (2012) Modelling neural correlates of working memory: a coordinate-based meta-analysis. Neuroimage 60:830846. CrossRef Medline

Santarnecchi E, Polizzotto NR, Godone M, Giovannelli F, Feurra M, Matzen L, Rossi A, Rossi S (2013) Frequency-dependent enhancement of fluid intelligence induced by transcranial oscillatory potentials. Curr Biol 23:1449-1453. CrossRef Medline

Santarnecchi E, Muller T, Rossi S, Sarkar A, Polizzotto NR, Rossi A, Kadosh RC (2016) Individual differences and specificity of prefrontal gamma frequency-tACS on fluid intelligence capabilities. Cortex 75:33-43. CrossRef

Sauseng P, Klimesch W, Freunberger R, Pecherstorfer T, Hanslmayr S, Doppelmayr M (2006) Relevance of EEG alpha and theta oscillations during task switching. Exp Brain Res 170:295-301. CrossRef Medline

Schutter DJ, van Honk J (2005) Electrophysiological ratio markers for the balance between reward and punishment. Cogn Brain Res 24:685-690. CrossRef Medline
Sela T, Kilim A, Lavidor M (2012) Transcranial alternating current stimulation increases risk-taking behavior in the balloon analog risk task. Front Neurosci 6:22. CrossRef

Selten R, Sadrieh A, Abbink K (1999) Money does not induce risk neutral behavior, but binary lotteries do even worse. Theor Decis 46:213-252.

Starcke K, Pawlikowski M, Wolf OT, Altstötter-Gleich C, Brand M (2011) Decision-making under risk conditions is susceptible to interference by a secondary executive task. Cogn Process 12:177182. CrossRef

Strüber D, Rach S, Neuling T, Herrmann CS (2015) On the possible role of stimulation duration for after-effects of transcranial alternating current stimulation. Front Cell Neurosci 9:311. CrossRef Medline

Swick D, Ashley V, Turken U (2011) Are the neural correlates of stopping and not going identical? Quantitative meta-analysis of two response inhibition tasks. Neuroimage 56:1655-1665. CrossRef

Thut G, Schyns P, Gross J (2011) Entrainment of perceptually relevant brain oscillations by non-invasive rhythmic stimulation of the human brain. Front Psychol 2:170. CrossRef Medline

Turi Z, Ambrus GG, Janacsek K, Emmert K, Hahn L, Paulus W, Antal A (2013) Both the cutaneous sensation and phosphene perception are modulated in a frequency-specific manner during transcranial alternating current stimulation. Restor Neurol Neurosci 31:275285.

Tversky A, Kahneman D (1985) The framing of decisions and the psychology of choice. In: Environmental impact assessment, technology assessment, and risk analysis, pp 107-129. Berlin, Heidelberg: Springer.

Veniero D, Vossen A, Gross J, Thut G (2015) Lasting EEG/MEG aftereffects of rhythmic transcranial brain stimulation: level of control over oscillatory network activity. Front Cell Neurosci 9:477. CrossRef Medline

Verdejo-García AJ, Perales JC, Pérez-García M (2007) Cognitive impulsivity in cocaine and heroin polysubstance abusers. Addict Behav 32:950-966. CrossRef Medline

Vosskuhl J, Huster RJ, Herrmann CS (2015) Increase in short-term memory capacity induced by down-regulating individual theta frequency via transcranial alternating current stimulation. Front Hum Neurosci 9:257. CrossRef Medline

Weaver SM, Arrington CM (2013) The effect of hierarchical task representations on task selection in voluntary task switching. J Exp Psychol Learn Mem Cogn 39:1128. CrossRef Medline

Welsh MC, Peterson E, Jameson MM (2017) History of childhood maltreatment and college academic outcomes: indirect effects of hot execution function. Front Psychol 8:1091. CrossRef

Whitney P, Rinehart CA, Hinson JM (2008) Framing effects under cognitive load: the role of working memory in risky decisions. Psychon Bull Rev 15:1179-1184. CrossRef Medline

Yeomans MR, Brace A (2015) Cued to act on impulse: more impulsive choice and risky decision making by women susceptible to overeating after exposure to food stimuli. PLoS One 10:e0137626. CrossRef

Zhang D, Gu R, Broster LS, Jiang Y, Luo W, Zhang J, Luo Y (2014) Linking brain electrical signals elicited by current outcomes with future risk decision-making. Front Behav Neurosci 8:84. CrossRef Medline 